\title{
Levantamento soroepidemiológico de leptospirose em trabalhadores do serviço de saneamento ambiental em localidade urbana da região sul do Brasil $^{*}$
}

\author{
Serological survey of leptospirosis among environmental sanitation workers in an \\ urban locality in southern Brazil
}

\author{
Laerte Pereira de Almeida*", Luís Fernando da Silva Martins ${ }^{\star \star \star}$, Claudiomar Soares Brod ${ }^{\star \star \star}$, Pedro \\ Manuel Leal Germano****
}

\begin{abstract}
ALMEIDA, L.P. de et al. Levantamento soroepidemiológico de leptospirose em trabalhadores do serviço de saneamento ambiental em localidade urbana da região sul do Brasil. Rev. Saúde Pública, 28: 76-81, 1994. A pesquisa de aglutininas anti-Leptospira, pela técnica de soroaglutinação microscópica, em soros de trabalhadores dos serviços de águas, bueiros e galerias, esgotos, coleta de lixo e limpeza pública, do Municipio de Pelotas, RS, Brasil, revelou 10,4\% de reagentes a um ou mais sorovares; não houve diferenças significantes entre as proporçòes de reagentes de cada um dos setores de trabalho. Foram identificados 12 sorovares diferentes; castelonis e australis, apesar de mais freqüentes, não apresentaram diferenças estatisticamente significantes com os demais. Constatou-se que $86,9 \%$ das amostras apresentavam títulos aglutinantes compreendidos entre 100 e 400; as proporções de soros com títulos iguais a 100 e 400 foram superiores às dos títulos $800,1.600$ e $3.200(\mathrm{p}<0,05)$.
\end{abstract}

Descritores: Leptospirose, epidemiologia. Trabalhadores. Saneamento urbano.

\section{Introdução}

A leptospirose, uma das zoonoses mais difundidas no mundo ${ }^{9}$, é endêmica no Brasil, sendo comum a ocorrência de surtos epidêmicos nas épocas de maior precipitação pluviométrica ${ }^{27}$.

Nos centros urbanos, a deficiência de saneamento básico constitui fator essencial para a proliferação de roedores ${ }^{1}$. Águas superficiais contami-

* Extraido da Dissertação de Mestrado intitulada "Estudo retrospectivo de reservatórios animais e vias de transmissão para leptospirose em cinco categorias de trabalhadores" apresentada à Faculdade de Veterinária da Universidade Federal de Pelotas em 1991.

** Faculdade de Saúde Pública da Universidade de São Paulo (doutorando) e Secretaria da Saúde do Estado de Minas Gerais - Minas Gerais, MG - Brasil

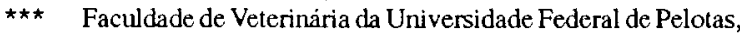
Pelotas, RS - Brasil

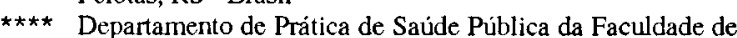
Saúde Pública da Universidade de São Paulo - São Paulo, SP - Brasil

Separatas/Reprints: P.M.L. Germano - Av. Dr. Amaldo, 715 01246-904 - São Paulo, SP - Brasil

Ediçāo subvencionada pela FAPESP. Processo 94/0500-0 nadas com Leptospira interrogans, eliminadas pela urina de ratos infectados, são a principal via de transmissão da enfermidade para o homem e para os animais. Portanto, os grupos socioeconômicos menos privilegiados, com dificuldade de acesso à educação e saúde, habitando moradias precárias, em regiōes periféricas às margens de córregos ou esgotos a céu aberto, expostos com freqüência a enchentes, são os que apresentam maior risco de contrair a infecçãol.

A leptospirose é, também, considerada como uma doença de risco ocupacional, atingindo diferentes categorias profissionais, como trabalhadores em arrozais e canaviais ${ }^{16}$, minas, abatedouros ${ }^{12} \mathrm{e}$ saneamento, além de tratadores de animais ${ }^{5,31} \mathrm{e}$ médicos veterinários ${ }^{4,20,22,27}$. Em relação aos serviços de saneamento, estão expostos à infecção não só os trabalhadores das redes de abastecimento de água e de esgotos, como também os da limpeza pública, coletores de lixo e varredores ${ }^{1}$. Essas atividades são executadas, na ausência de recursos tecnológicos e de equipamentos de segurança, por mào-de-obra desqualificada e mal remunerada, o que aumenta ainda mais o risco dos trabalhadores contrairem a infecção $0^{2,11,19,30}$. 
Na Alemanha, em 1961, entre trabalhadores do serviço de Coleta de Lixo foram detectados 7,4\% de reagentes à pesquisa de aglutininas anti-Leptospira, e $0,9 \%$ entre os funcionários da limpeza pública ${ }^{15}$. Pesquisa realizada, em 1985 , com grupo de alto risco, constituido por funcionários do Departamento de Controle de Roedores da cidade de Detroit, nos EUA, evidenciou freqüència de reagentes, contra o sorovar icterohaemorrhagiae, superior ao do grupo não exposto ao risco ocupacional ${ }^{13}$. Já na Itália, em 1986, foram encontrados $16,7 \%$ de reagentes entre varredores do serviço de limpeza pública ${ }^{12}$.

No Brasil, levantamento epidemiológico realizado na cidade de São Paulo, em 1962, revelou $28,5 \%$ de reagente à prova de soroaglutinação para leptospirose, entre trabalhadores dos serviços de desobstrução e ligação de esgotos ${ }^{25}$. No Estado do Rio Grande do Sul, em 1962, foram identificados 2,3\% de reagentes entre trabalhadores de esgotos, predominando os sorovares canicola, icterohaemorrhagiae e copenhageni ${ }^{14}$. Na cidade de Porto Alegre, em 1966, foram encontrados 19,2\% de positivos, também em trabalhadores de esgotos, identificando-se os sorovares icterohaemorrhagiae, australis e sentot ${ }^{10}$. Em 1967, no Estado de São Paulo foram encontrados $3,16 \%$ de reagentes entre funcionários de limpeza pública, com predominância do sorovar icterohaemorrhagiae. Em 1970, 9,7\% dos trabalhadores da cidade de São Paulo em limpeza pública e $0,5 \%$ dos da rede de esgoto eram reagentes à sorologia para leptospirose, sendo os sorovares mais freqüentes: icterohaemorrhagiae, canicola, pomona, poi e andamana ${ }^{28}$. Estudo retrospectivo dos acidentados de trabalho por leptospirose, atendidos no hospital Emilio Ribas de São Paulo, no período de 1982 a 1986, revelou que os coletores de lixo constituíam uma das categorias mais atingidas ${ }^{23}$.

Assim, com base nesses aspectos, objetiva-se no presente trabalho determinar a prevalência de infecção leptospirica entre trabalhadores de 5 categorias do serviço de saneamento ambiental, a saber: águas, bueiros e galerias, esgotos, coleta de lixo e limpeza pública. Complementarmente, procurarse-á caracterizar as amostras soropositivas quanto à magnitude dos títulos e identificar os tipos de sorovares de maior prevalência no grupo de profissionais pesquisado.

\section{Material e Método}

\section{Soros}

Foram utilizadas 386 amostras de soro, colhidas de funcionários do serviço de saneamento ambiental do Município de Pelotas, Estado do Rio Grande do Sul, em setembro de 1989, assim distribuídas em relação às categorias de trabalho: 24 do serviços de águas, 35 de bueiros e galerias, 37 de esgotos, 66 da coleta de lixo e 224 da limpeza pública. $O$ total de amostras correspondeu a, aproximadamente, $71 \%$ do efetivo de trabalhadores lotados no citado serviço.

\section{Técnica}

Utilizou-se a técnica de aglutinação microscópica para a pesquisa de aglutininas anti-Leptospira nas amostras de $\operatorname{soros}^{29}$, empregando-se uma bateria de 27 antígenos vivos cultivados em meio EMJH enriquecido* e titulo diagnóstico igual a $100^{1}$. Nos casos de coaglutinação, considerou-se o sorovar correspondente ao soro em que se obteve o título máximo ${ }^{25}$; quando da coincidência de títulos na coaglutinação optou-se pela eliminação dos so$\operatorname{ros}^{24,32}$, por não haver condiçōes para a execução das provas de absorção de aglutininas com os sorovares envolvidos.

\section{Análise estatistica}

Aplicou-se, aos resultados obtidos, o teste de duas proporções, com aproximação normal, para avaliar os níveis estatísticos de significância (alfa igual a 5\%) entre as diferenças registradas nas categorias de trabalho estudadas, nas freqüências de ocorrência de cada sorovar, em relação aos demais, e nas proporções dos títulos aglutinantes ${ }^{3}$.

\section{Resultados}

No grupo de profissionais, submetido à técnica de soroaglutinação microscópica, para a pesquisa de aglutininas anti-Leptospira, constituído por di-

* Difco Laboratories Detroit-USA. 
ferentes categorias do serviço de saneamento do Município de Pelotas, RS, constatou-se a ocorrência de 40 amostras reagentes $(10,4 \%)$ a um ou mais sorovares (Tabela 1). Em relação às categorias profissionais, as maiores freqüências de positividade foram observadas nos serviços de águas $(16,7 \%)$ e esgotos $(16,2 \%)$; em contrapartida, foi no serviço de limpeza pública que se registrou a menor freqüência de positividade (7,6\%). Contudo, essas diferenças não se revelaram estatisticamente significantes.

Das 40 amostras de soros reagentes, 12 $(30,0 \%)$ aglutinaram com um único sorovar, observando-se 3 casos $(25,0 \%)$ com castelonis e outros $3(25,0 \%)$ com australis; 2 casos $(16,6 \%)$ com djasiman; e um caso de cada $(8,3 \%)$ com panama, pyrogenes, shermani e pomona. Essas diferenças não foram estatisticamente significantes.
Tabela 1. Soros de funcionários do serviço de saneamento ambiental do Municipio de Pelotas, RS, submetidos à técnica de soroaglutinação microscópica, para a pesquisa de aglutininas anti-Leptospira, segundo a categoria profissional $e$ as freqüências de positividade, 1989.

\begin{tabular}{lccc}
\hline & \multicolumn{2}{c}{ Soros } & \\
\cline { 2 - 4 } Categoria & & \multicolumn{2}{c}{ Positivos } \\
\cline { 2 - 4 } Profissional & Examinados & f & $\%$ \\
\cline { 2 - 4 } & & & \\
& & 4 & 16,7 \\
Aguas & 24 & 6 & 16,2 \\
Esgotos & 37 & 9 & 13,6 \\
Coleta de Lixo & 66 & 4 & 11,4 \\
Bueiros $\ominus$ Galerias & 35 & 17 & 7,6 \\
Limpeza Pública & 224 & 40 & 10,4 \\
\hline Total & 386 & &
\end{tabular}

Tabela 2. Soros de funcionários do serviço de saneamento ambiental do Município de Pelotas, RS, positivos à pesquisa de aglutininas anti-Leptospira pela técnica de soroaglutinaçāo microscópica, segundo os sorovares e a magnitude dos respectivos títulos, 1989

\begin{tabular}{|c|c|c|c|c|c|c|c|c|}
\hline \multirow{2}{*}{ Sorovares } & \multicolumn{6}{|c|}{ Títulos } & \multirow{2}{*}{ Total } & \multirow{2}{*}{$\%$} \\
\hline & 100 & 200 & 400 & 800 & 1.600 & 3.200 & & \\
\hline Castelonis & 2 & 1 & - & - & - & 1 & 4 & 17,4 \\
\hline Australis & 2 & - & 2 & - & - & - & 4 & 17,4 \\
\hline Djasiman & 2 & - & - & - & - & - & 2 & 8,7 \\
\hline Panama & 1 & - & - & - & - & - & 1 & 4,3 \\
\hline Pomona & 1 & - & - & 1 & - & - & 2 & 8,7 \\
\hline Pyrogenes & - & - & 1 & - & - & - & 1 & 4,3 \\
\hline Shermani & - & - & 1 & - & - & - & 1 & 4,3 \\
\hline Icterohaemormagiae & - & - & 2 & - & - & - & 2 & 8,7 \\
\hline Copenhageni & - & 2 & - & - & - & - & 2 & 8,7 \\
\hline Sejroe & - & 2 & - & - & - & - & 2 & 8,7 \\
\hline Cynopteri & - & - & - & - & 1 & - & 1 & 4,3 \\
\hline Autumnalis & - & - & 1 & - & - & - & 1 & 4,3 \\
\hline Total & 8 & 5 & 7 & 1 & 1 & 1 & 23 & $-100,0$ \\
\hline Percentual & 34,8 & 21,7 & 30,4 & 4,3 & 4,3 & 4,3 & $* 100,0$ & \\
\hline
\end{tabular}

\footnotetext{
*alor aproximado
} 
Das 28 amostras de soros que coaglutinaram com dois ou mais sorovares, $11(39,3 \%)$ apresentaram títulos máximos não coincidentes. Assim, observaram-se os sorovares cophenhageni, sejroe e icterohaemorrhagiae, cada um deles em duas amostras (18,2\%), e pomona, cynopteri, autumnalis, australis e castelonis, em cada uma das amostras restantes $(9,1 \%)$. Estatisticamente estas diferenças não foram significantes.

$\mathrm{Na}$ Tabela 2 são apresentados os 12 sorovares identificados nos 11 soros coaglutinantes, com titulo máximo não coincidente, e nos 12 soros em que houve aglutinação de um único sorovar, e os respectivos títulos aglutinantes. Com base nos resultados da tabela, pode-se constatar que os sorovares castelonis e australis foram os mais freqüentes (4 casos cada um ou $17,4 \%$ ); os demais sorovares foram identificados nas 15 amostras restantes. $A$ análise estatística, também, não evidenciou diferenças significantes entre as proporções de cada um dos sorovares.

Com relação à magnitude dos títulos aglutinantes, ainda de acordo com a Tabela 2 , verifica-se que $86,9 \%$ das amostras apresentaram títulos compreendidos entre 100 e 400 . As diferenças observadas entre as proporções correspondentes aos títulos 100 e 400 somente foram significantes do ponto de vista estatístico $(\mathrm{p}<0,05)$ quando comparadas a dos títulos $800,1.600$ e 3.200 .

\section{Discussão e Conclusões}

A prevalência de infecção leptospírica registrada entre os trabalhadores do serviço de saneamento ambiental do Municipio de Pelotas, RS $(10,4 \%)$, situou-se entre as mais elevadas das já registradas em inquéritos sorológicos no Brasil. Contudo, esta taxa é coerente com os resultados obtidos por outros pesquisadores nacionais para o grupo estudado $^{10,25,28}$, onde se registraram valores que variaram desde $9,7 \%^{28}$ até $28,5 \%{ }^{25}$. No que se refere a outros tipos de atividades, como trabalhadores do campo ${ }^{16,28}$, lavradores de arrozais ${ }^{7,14}$, cortadores de cana ${ }^{21}$, magarefes ${ }^{6,14}$, e mineiros ${ }^{14}$, as taxas observadas são menores, variando de $0,9 \%^{21}$ até um máximo de $5,7 \%{ }^{28}$.

Esses resultados comprovam que os profissionais envolvidos com atividades de saneamento, apresentam risco considerável de contrair leptospirose, pois têm contato direto com elementos do meio ambiente, facilmente contamináveis pela urina de roedores e mesmo de carnívoros domésti$\cos ^{17,24}$, que propiciam a manutenção da viabilidade das $L$. interrogans por várias horas; e que, na dependência da densidade populacional desses animais, possibilitam a contaminação quase permanente do ambiente. Levantamento soroepidemiológico, realizado com funcionários do biotério do campus de Ribeirão Preto da Universidade de São Paulo ${ }^{5}$, revelou prevalência de infecção leptospírica da ordem de $11,4 \%$, mostrando o risco a que estão submetidos trabalhadores com acesso a excreções, notadamente de roedores. O mesmo já havia sido constatado em Detroit, EUA, entre funcionários do Departamento de Controle de Roedores ${ }^{13}$. Ao lado dessas constatações, deve-se considerar, ainda, que os trabalhadores envolvidos com essas atividades não apresentam qualquer grau de especialização e provêm de grupos sociais com baixos padrões de educação e saúde ${ }^{2,19}$.

Com relação às taxas de positividade verificadas entre as diferentes categorias de trabalhadores (Tabela 1), estatisticamente não se verificou predominância de infecção leptospírica de uma determinada categoria sobre a outra, o que pressupõe, que qualquer uma dessas atividades expõe os individuos ao risco da infecção. Contudo, a prevalência de infeç̧ão verificada entre os trabalhadores do serviço de águas, $16,2 \%$, é bem superior às observadas em outros estudos realizados em Belo Horizonte, $\mathrm{MG}^{26}$, e Sorocaba, $\mathrm{SP}^{18}$, respectivamente $1,4 \%$ e $3,4 \%$. Do mesmo modo, a taxa de infecção dos coletores de lixo, 13,6\%, também é superior à registrada por outros autores no Estado de São Paulo ${ }^{8}$, de $3,16 \%$. Os valores obtidos para os serviços de esgotos $(16,2 \%)$, bueiros e galerias $(11,4 \%)$ e limpeza pública $(7,6 \%)$, estão em consonância com os obtidos em outros levantamentos soroepidemiológicos $8,14,23,25,28$.

Nas 23 amostras estudadas foram identificados 12 sorovares (Tabela 2), o que explica a ausência de diferenças estatisticamente significantes entre as proporções de cada um deles. Contudo, castelonis $(17,4 \%)$ e australis $(17,4 \%)$ foram os sorovares mais freqüentemente encontrados entre os trabalhadores do Município de Pelotas. Pesquisas semelhantes têm demonstrado que os sorovares ictero- 
haemorrhagiae e canicola apresentam prevalência elevada no Brasil ${ }^{8,10,14,25}$, ao lado dos sorovares poi $^{28}$ e copenhageni ${ }^{27}$. O sorovar castelonis só foi encontrado com elevada prevalência, 50,0\% dos sotos reagentes, entre funcionários do biotério do campus de Ribeirão Preto da Universidade de São Paulo ${ }^{5}$, diretamente expostos a diferentes espécies de roedores. No presente estudo, porém, os sorovares icterohaemorrhagiae e copenhageni foram identificados, cada um, em dois soros $(8,7 \%)$; enquanto que canicola e poi não foram encontrados em qualquer uma das amostras reagentes.

No que concerne à magnitude dos títulos $(\mathrm{Ta}-$ bela 2), verifica-se que a maioria, $56,5 \%$ dos soros, apresentou valores iguais a $100(34,8 \%)$ e 200 $(21,7 \%)$, considerados baixos, possivelmente expressando casos de infecção passada ou recém instalada. Por outro lado, $44,5 \%$ dos títulos obtidos foram iguais ou superiores a 400 , o que pode representar casos de infecções manifestas ou compatíveis com enfermidade clínica. Deve-se destacar que estes percentuais são concordantes com os obtidos, em levantamentos anteriores ${ }^{25,26}$.

No município estudado, a Leptospira interrogans está presente no meio ambiente, representada por grande número de sorovares. Os trabalhadores do serviço de saneamento ambiental estão, assim, expostos ao risco da infecção por lidarem, diuturnamente, com material passivel de contaminação por roedores. Do mesmo modo, as camadas menos favorecidas da população, também estão expostas a esse risco. Portanto, outros trabalhos deveriam ser levados a efeito, no sentido de avaliar, não só a contaminação ambiental em pontos críticos, como também, a prevalência da infecção leptospírica em outros grupos de risco.

ALMEIDA, L.P. de et al. [Serological survey of leptospirosis among environmental sanitation workers in an urban locality in southern Brazill]. Rev. Saúde Pública, 28: 76-81, 1994. Sera from 386 environmental sanitation workers, concerned with water supply, drains and drainage galleries, sewers, garbage collection and road sweepers, were examined for leptospiral agglutinins by the microscopic agglutination test. Altogether 40 of the 386 workers $(10.4 \%)$ were positive to one or more serovars; however, the difference in seropositivity between the professional categories was not significant $(p>0.05)$. Twelve serovars were recorded among the seropositive workers with predominance of $L$. castelonis and $L$ australis; but the difference between the serovars was not statistically significant $(p>0.05)$. Of the seropositive workers, $86.9 \%$ had agglutination titres $\geq 100$ and $\leq 400$; the rates for titres 100 and 400 were higher than $800,1,600$ and 3,200 (p < $0.05)$.

Keywords: Leptospirosis, epidemiology. Workers. Urban sanitation.

\section{Referèncias Bibliográficas}

1. ALMEIDA, L.P. Estudo retrospectivo de reservatórios animais e vias de transmissão para leptospirose em cinco categorias de traballhadores. Pelotas, 1991. [Dissertação de Mestrado - Faculdade de Veterinárias da UFP].

2. ANDRADE, J. \& BRANDĀO, A. Contribuição ao conhecimento da epidemiologia da leptospirose humana, com especial referência ao Grande Rio, Brasil, no periodo de 1970 a 1982. Mem. Inst. Oswaldo Cruz, 82:91-100, 1987.

3. BERQUÓ, E.S. et al. Bioestatística. São Paulo, EPU, 1981.

4. BOLIN, C.A. \& KOELLNER, P. Human-to-human transmission of Leptospira interrogans by milk. J. Infect. Dis., 158:246-7, 1988.

5. CAPUANO, A.D. et al. Prevalência de infecção leptospirótica em funcionários do biotério do campus de Ribeirão Preto da USP. Medicina (Ribeirão Preto), 19:103-10, 1986.

6. CASTRO, A.F.P. et al. Pesquisa de aglutininas anti-leptospiras entre magrefes em alguns municípios do estado de Sāo Paulo. Rev. Inst. Med. Trop. São Paulo, 8:287-90, 1966.

7. CORREA, M.O.A. et al. Inquérito sorológico para diagnóstico de leptospirose entre lavradores de arrozais do vale do Rio Paraiba. Rev. Inst. Adolfo Lutz 14:33-7, 1954.

8. CORREA, M.O.A. et al. Inquérito sorológico para leptospirose entre trabalhadores na limpeza pública na cidade de São Paulo. [Resumo]. Rev. Paul Med., 70:102, 1967.

9. CORREA, M.O.A. et al. Leptospiroses. In: Veronesi, R. Doenças infecciosas e parasitárias. 6.ed. Rio de Janeiro, Guanabara Koogan, 1976. p. 787-807.

10. COSTA, E.A. Investigação epidemiológica de leptospiroses em trabalhadores do Departamento Municipal de Aguas e Esgotos (D.M.A.E.) de Porto Alegre. Porto Alegre, 1966. [Tese de Doutorado - Faculdade Católica de Medicina de Porto Alegre].

11. COSTA, E.A. et al. Aspectos epidemiológicos da leptospirose em Salvador, Bahia. Bol. Epidemiol., 2:57-61, 64-8, 1970.

12. CREVATIN, D. et al. Serosourvey on the presence of leptospiral agglutinins in humans in Northem Italy. Eur. J. Epidemiol.,2:44-7, 1986.

13. DEMERS, R.Y. et al. Leptospiral exposure in Detroit rodent control workers. Am. J. Public Health, 75:1090-91, 1985.

14. EDELWEISS, E.L. Leptospiroses humanas: contribuição ao seu estudo. Porto Alegre, 1962. [Tese de Livre-Docência Faculdade de Medicina de Porto Alegre da UFRGS].

15. FUCHS, G.H.P. Zur problematik arbeitsbedingter leptospireninfektionen bei Angehorigen seg Schmutzberufe. Zentralb. Bakt., 180:549-61, 1960.

16. GALE, D.A. et al. Leptospiral antibodies in patientes from a barbadian general practice. Eur. J. Epidemiol., 6:150-5, 1990. 
17. GENDRON, Y. et al. Les leptospiroses en Polynesie Française: étude de 120 observations. Med. Trop. (Mars.), 52:21-7, 1992.

18. GOMES, M.C.O. et al. Investigação sobre a ocorrência de leptospirose em trabalhadores de diversas profissões no distrito sede do município de Sorocaba. Rev. Inst. Adolfo Lutz, 28:19-26, 1968.

19. GONÇALVES, A.J.R. et al. Leptospiroses - revisão de 90 pacientes internados no Hospital Estadual de São Sebastião (Rio de Janeiro), no período de janeiro/76 a dezembro/77. Folha Med., 82:93-102, 1981.

20. HODGEN, A.N. \& STUCKEY, M.S. Lepstospirosis in Western Australia 1983-1984. Med. J. Aust., 144:567-9, 1986.

21. HYAKUTAKE, S. et al. Inquérito sorológico para o diagnóstico de leptospirose entre cortadores de cana de açúcar de alguns municípios do estado de São Paulo. Rev. Inst. Adolfo Lutz, 25/27:111-4, 1965/1967.

22. KINGSCOTE, B.F. Lepitospirosis in two veterinarians. Can. Med Assoc. J., 133:879-80, 1985.

23. KURCHNAROFF, T.M. et al. Acidentes de trabalho por leptospirose: estudo retrospectivo de casos de leptospirose adquirida no exercício da profissão nos anos de 1982, 1984, 1985 e 1986. [Comunicaçāo] Rev. Soc. Bras. Med. Trop., 21 (supl) 126, 1988.

24. LARSSON, C.E. Estudo epidemiológico da leptospirose felina. São Paulo, 1981. [Tese de Doutorado - Faculdade de Saúde Pública da USP].

25. MAGALDI, C. Contribuição à epidemiologia das leptospiroses, investigação em trabalhadores da rede de águas e esgotos da cidade de Sāo Paulo. São Paulo, 1962. [Tese de Doutorado - Faculdade de Medicina da USP].

26. NOHMI, N. Contribuição à epidemiologia das leptospiroses: investigação em trabalhadores da rede de águas e esgotos, armazéns, restaurantes e feiras livres da cidade de Belo Horizonte, MG. Hospital, 65:617-29, 1964.

27. SAKATA, E.E. et al. Sorovares de Leptospira interrogans isolados de casos de leptospirose humana em São Paulo, Brasil. Rev. Inst. Med. Trop. São Paulo, 34:217-21, 1992.

28. SANTA ROSA, C.A. et al. Pesquisa de aglutininas anti-Leptospira em soros de trabalhadores de diversas profissoes. Rev. Microbiol., 1:19-24, 1970a.

29. SANTA ROSA, C.A. Diagnóstico laboratorial das leptospiroses. $R$ Microbiol., 1:97-107, 1970b.

30. SILVA, J.J.P. et al. Estudo preliminar das leptospiroses no estado do Rio de Janeiro. Rev. Soc. Bras. Med. Trop., 2:317-37, 1968.

31. SKILBECK, N.W. \& MILLER, G.T. A serological survey of leptospirosis in Gippslande dairy farmers. Medical $J$. Aust., 144:565-7, 1986.

32. YASUDA, P.H. Leptospirose em cães errantes da cidade de São Paulo. São Paulo, 1979. [Tese de Doutorado - Instituto de Ciências Biomédicas da USP].

Recebido para publicação em 19.8.1993 Aprovado para publicaçấo em 30.11 .1993 